\title{
FALSAS MEMÓRIAS: A REPERCUSSÃO DA FALIBILIDADE DA MEMÓRIA HUMANA NA PROVA DO DIREITO DAS FAMÍLIAS E NOS DIREITOS DA PERSONALIDADE
}

\author{
Carlos Alexandre Moraes ${ }^{1}$ \\ Juliani Bruna Leite Silva ${ }^{2}$
}

\section{RESUMO}

O presente artigo tem por escopo analisar o impacto dos aspectos frágeis advindos da memória humana no Direito Processual das Famílias, em especial, nas provas dependentes da memória, bem como, nos direitos da personalidade. A memória humana é inexata, restrita e pode incorrer em alguns vícios, dentre eles o fenômeno das falsas memórias: recordações de fatos irreais, isto é, a lembrança de fatos que nunca ocorreram ou que aconteceram de forma diversa da qual é relembrada. Dessa forma, por meio do método dedutivo e mediante uma revisão bibliográfica interdisciplinar constata-se que apesar da aparência acanhada, ao abordar as memórias falsificadas dentro de uma ótica jurídica, é possível reconhecer o seu caráter danoso e perpetrador de desrespeito a diretos.

PALAVRAS-CHAVE: Direitos da personalidade; Direito Processual das Famílias; Falsas memórias; Memória; Prova.

\section{FALSE MEMORIES: THE REPERCUSSION OF THE FALIBILITY OF HUMAN MEMORY IN THE PROOF OF THE RIGHT OF FAMILIES AND IN THE RIGHTS OF PERSONALITY}

\begin{abstract}
This article aims to analyze the impact to fragile aspects arising from human memory on Family procedural law in particular, in evidence dependente on memory, as well as on personality rights. Human memory in inaccurate, restricted and may incur some vices, among them the phenomenon of false memories: memories of unreal facts, memories of unreal facts, that is, the recollection of facts that never occurred or that happened differently from which it is recalled.Thus through the deductive method and Through na interdisciplinar bibliographic review, it is observed that despite the shy apperance, by addressing the falsified memories within a legal perspective, it is possible to recognizer their harmful character and perpetrator of disrespect of direct.
\end{abstract}

\footnotetext{
${ }^{1}$ Professor Permanente do Programa do Mestrado em Direito da Universidade Cesumar (UniCesumar); PósDoutor em Direito pelo Centro Universitário Cesumar (UniCesumar), Doutor em Direito pela FADISP; Doutor em Ciências da Educação pela UPAP; Mestre em Direito pelo Centro Universitário Cesumar (UniCesumar); Pesquisador Bolsista - Modalidade Produtividade em Pesquisa para Doutor PPD - do Instituto Cesumar de Ciência, Tecnologia e Inovação (ICETI); Advogado; Meembro do IBDFAM, Vice-presidente do IBDCONT no Estado do Paraná e Membro do IBERC, E-mail: camoraes.adv@hotmail.com

${ }^{2}$ Mestranda em Ciências Jurídicas junto ao Programa de Pós-Graduação em Ciências Jurídicas (PPGCJ) da Universidade Cesumar (UniCesumar), na linha de pesquisa com enfoque nos Direitos da Personalidade e o seu alcance na contemporaneidade. Pós-Graduanda em Direito de Família e sucessões pela EBRADI. Graduada em Direito pelo Centro Universitário de Maringá (UniCesumar). Lattes: http://lattes.cnpq.br/9428994151607919, ORCID: https://orcid.org/0000-0003-3723-0486/ E-mail: julianibruna@hotmail.com
} 
KEY-WORDS: Personality rigths; Family procedural Law; False memories; Memory; Proof.

\section{INTRODUÇÃO}

Confiável e ilimitada, são alguns dos adjetivos atribuídos a memória pelo senso comum, todavia, a memória humana é, por comprovação científica, imperfeita e suscetível à falhas, prova disso manifesta-se no esquecimento, assim como, na possibilidade de incorporação de memórias falsas. Nesse prisma, as falsas memórias são lembranças de eventos improcedentes, em outras palavras, fatos que são recordados mas que nunca ocorreram ou aconteceram de forma distinta da qual é relembrada.

No Direito das Famílias é possível que haja a propiciação de ambiente plenamente apto ao fornecimento das condições necessárias para a formação de uma memória falsificada, seja em seu contexto interno, como em práticas de alienação parental ou em sede de conflitos, isto é, na esfera processual, em especial, no que tange a atividade probatória, o foco do presente artigo. Dessa forma, a análise das falsas memória sob a perspectiva dos seus efeitos para a seara jurídica, mostra o quão danoso esse fenômeno pode ser.

Por isso, o presente artigo tem como problemática de pesquisa, as seguintes indagações: Como as falsas memórias podem repercutir dentro do sistema probatório do Direito das Famílias? Ainda, é possível falar na violação dos direitos da personalidade diante de tal conjuntura?

No tocante as hipóteses de pesquisa, referencia-se as sequentes: a) as falsas memórias podem ocorrer em um contexto de litígio familiar em sede processual, principalmente, nos elementos e momentos que dizem respeito a prova e b) tal circunstância pode promover uma efetiva violação aos direitos da personalidade daqueles que são prejudicados com a ocorrência das memórias falsas.

A temática que gravita em torno das falsas memórias, vem sendo estudada progressivamente, contudo, as pesquisas acerca do assunto são, em sua maioria, de ordem processual penal, de modo que as produções científicas e interdisciplinares sobre o assunto, correlacionadas às relações familiares, ainda não são numerosas, tendo em vista que o tema é 
de extrema valia e que conta, inclusive, com sérias repercussões. Assim, é na referida observação que fundamenta-se a justificativa deste artigo.

Dito isso, cabe destacar que este trabalho é esquadrinhado em quatro tópicos. Sendo assim, em um primeiro momento, de maneira interdisciplinar, são observados a memória humana e o seu funcionamento, sendo demonstrado como este processo pode sofrer ingerências e fornecer vícios. Em seguida, as falsas memórias são devidamente conceituadas, também ante um enfoque interdisciplinar.

Posteriormente, são apresentas as repercussões das memórias falsas para o Direito Processual das Famílias. Dentro dessa planície, é elucidada a atividade probatória nas demandas judiciais familiares como esferas viabilizadoras de falsas memórias. Por fim, são abordados os efeitos de toda a referida circunstância para os direitos da personalidade dos envolvidos no enredo.

Para tanto, utiliza-se como método de abordagem o método dedutivo, partindo de uma perspectiva geral para uma particular, tendo como método de procedimento o analítico. Quanto a técnica de pesquisa, o presente artigo parte de uma documentação indireta, mediante uma pesquisa bibliográfica e documental, cujo o levantamento do referencial teórico advém da literatura nacional e internacional mediante busca em bases de dados e periódicos.

\section{UM ENFOQUE INTERDISCIPLINAR ACERCA DA MEMÓRIA HUMANA}

Para a devida reflexão sobre o problema de pesquisa proposto neste trabalho, é necessário trazer à luz conhecimentos interdisciplinares. Assim, a visualização dos impactos da falibilidade da memória humana no processo das famílias, exige saberes de algumas áreas distintas, no entanto, complementares pelo fato de a memória ser um processo complexo. Justamente nesse ponto, é possível enxergar a estima da interdisciplinaridade.

Desse modo, no estudo da memória humana é fundamental que além dos entendimentos da Neurociência, também seja recorrido ao saber da Psicologia Cognitiva, ambas aliadas à Ciência Jurídica. Uma vez agregados, é possível arquitetar um conhecimento novo e uno, promovendo um saber interdisciplinar. Nessa senda, de acordo com Hilton 
Japiassu (1976, p.31) “O interdisciplinar se apresenta como o remédio mais adequado à cancerização ou patologia geral do sabe”.

Conforme Ivani Fazenda (2011, p.70) "Em nível de interdisciplinaridade, ter-se-ia uma relação de reciprocidade, de mutualidade, ou melhor dizendo, um regime de copropriedade que iria possibilitar o diálogo [...]”. Sendo assim, na interdisciplinaridade, há a contribuição de diversas disciplinas, coadunas entre si, aqui o caráter interdisciplinar pode ser traduzido pela união do Direito, da Neurociência e da Psicologia Cognitiva.

\subsection{COMPREENDENDO O FUNCIONAMENTO DA MEMÓRIA HUMANA E A SUA FALIBILIDADE}

Destacada a necessidade do enfoque interdisciplinar, cabe adentrar à memória. O estudo da memória humana vem despertando intenso interesse ao longo da história, tanto é que há uma íntima ligação entre a memória e a escrita. De acordo com a colocação de Alcyr Oliveira (2007, p. 20) a escrita serviria de apoio para a memória, por trabalhar com a retenção de informações. Ainda na conclusão feita por Oliveira (2007, p. 20), a memória também desempenha um papel social, o autor frisa que a memória humana é responsável por uma parcela do funcionamento da própria sociedade.

Ivan Izquierdo (2004, p.15), médico e especialista no tema, conceitua a memória como sendo a “[...] aquisição, conservação e evocação de informações”. Consoante salienta Izquierdo (2018, p.1) a aquisição é a aprendizagem, já que só se memoriza aquilo que foi aprendido e a evocação diz respeito a recuperação daquilo que foi aprendido e posteriormente guardado.

O valor da memória para o ser humano é profundo, uma vez que há a necessidade de o seu uso para as mais simples operações cotidianas até para as mais elaboradas. Ivan Izquierdo (2018, p.1) frisa que "O conjunto das memórias de cada um determina aquilo que se denomina personalidade ou forma de ser”, sendo assim, a memória também pode ser entendida como um fator que promove a individualização de sujeitos, visto que " [...] a 
coleção pessoal de lembranças de cada indivíduo é distinta das demais, é única" (IZQUIERDO, 2018, p.1).

Sendo um processo de conservação e de acesso à experiências, a memória tem algumas fases, em regra, são elas: I) codificação; II) armazenagem e III) recuperação. Para Robert Sternberg (2008 p. 156) “[...] Na codificação, transformam-se dados sensoriais em uma forma de representação mental. Na armazenagem mantêm-se informações codificadas na memória. Na recuperação, você retira ou usa informações armazenadas na memória".

Abordados o conceito e as fases da memória, da mesma maneira que aludida a relevância, em nível social e individual, da memória humana, torna-se necessário acentuar que apesar de imprescindível, a memória humana é falha e imperfeita.

Nas lições de Antonio Damásio (2001, p.118-119) é possível notabilizar como ocorre o armazenamento da memória. Nesse sentido:

\begin{abstract}
As imagens não são armazenadas sob a forma de fotografias fac-similares de coisas, de acontecimentos, de palavras ou de frases. $\mathrm{O}$ cérebro não arquiva fotografias Polaroid de pessoas, objetos, paisagens; nem armazena fitas magnéticas com música e fala; não armazena filmes de cenas de nossa vida; nem retém cartões com "deixas" [...]. Em resumo, não parecem existir imagens de qualquer coisa que seja permanentemente retida, mesmo em miniatura, em microfichas, microfilmes ou outro tipo de cópias. Dada a enorme quantidade de conhecimento que adquirimos durante a vida, qualquer tipo de armazenamento fac-similar colocaria provavelmente problemas insuperáveis de capacidade. Se o cérebro fosse como uma biblioteca convencional, esgotaríamos suas prateleiras à semelhança do que acontece nas bibliotecas. Além disso, o armazenamento fac-similar coloca também problemas difíceis de eficiência do acesso à informação. Todos possuímos provas concretas de que nem sempre recordamos um dado objeto, um rosto ou uma cena, não obtemos uma reprodução exata, mas antes uma interpretação, uma nova versão reconstruída do original. Mais ainda, à medida que a idade e experiência se modificam, as versões da mesma coisa evoluem.
\end{abstract}

Dessa forma, o armazenamento de informações na memória não é absoluto, visto que a memória não tem capacidade para tanto, isso significa dizer que a memória humana não retém todos os eventos e fatos, nem todas as experiências e informações de modo íntegro, pleno ou então puro. Na realidade, o que se tem é que há uma representação do evento original, ou seja, a memória recorda uma nova versão daquela experiência vivenciada. 
Para Roediger e McDermott (2000, p. 126) “Memories are not recordings but rather recodings; that is; they are not audio or vídeo recordings but a recoded blend of events from the external world, as interpreted by each person's unique schemata"3. Segundo os autores, a memória não é semelhante à uma gravação de áudio ou vídeo e sim uma recodificação de eventos passados, o que demonstra a sua natureza imperfeita.

De acordo com John Kihlstrom (1998) "[...] that memories can be distorted, biased, and otherwise changed by changes in perspective and other events that occur after the time $o f^{\prime 4}$. Kihlstrom trabalha com a ideia de que a memória funciona como escrever um livro com base em notas fragmentadas e não em ler um livro. Diante dessa analogia, é possível entender que o processo de leitura é uniforme, já no processo de escrita, novos eventos podem ser incorporados.

Pelo fato de a memória humana não possuir capacidade de absorver todo o acervo de informações obtido, ela passa por processos de esquecimento e é suscetível à incorporações de elementos falsos.

Acerca do assunto Ivan Izquierdo (2018, p.8) sublinha que:

Nossa memória pessoal e coletiva descarta o trivial e, às vezes, incorpora fatos irreais. Vamos perdendo, ao longo dos dias e dos anos, aquilo que não interessa, aquilo que não nos marcou: ninguém se lembra do ano em que foi construída aquela casa feia do outro quarteirão ou de onde morava aquele colega da escola com quem tivemos pouco contato. Não costumamos lembrar sequer detalhes da tarde de ontem. Mas também vamos incorporando, ao longo dos anos, mentiras e variações que geralmente as enriquecem.

Logo, a memória humana possui uma função essencial, norteando a vida humana e consequentemente, a própria sociedade. No entanto, a memória é um processo vulnerável de obtenção, retenção e recordação de informações, prova para essa colocação reside no esquecimento e na incorporação de fatos irreais sofridos pela memória, como as falsas memórias, que serão abordadas a seguir.

\footnotetext{
3 “As memórias não são gravações, mas sim recodificações; isto é, eles não são gravações de áudio ou vídeo, mas uma mistura recodificada de eventos do mundo externo, conforme interpretados pelos esquemas únicos de cada pessoa" (ROEDIGER; MCDERMOTT, 2000, p.126, tradução nossa).

4 “[...] as memórias podem ser distorcidas, tendenciosas, e de outra forma alterado por mudanças na perspectiva e outros eventos que ocorrem após o tempo de codificação" (KIHLSTROM, 1998, tradução nossa).
} 


\section{COMPREENDENDO O QUE SÃO AS FALSAS MEMÓRIAS}

O fenômeno das falsas memórias tem provocado instigações crescentes já há muito tempo e o interesse no tema tem se intensificado ainda mais nos últimos anos, especialmente por conta da conclusão de que as memórias falsificadas podem gerar repercussões drásticas e ao observar os seus resultados pelo prisma jurídico, é possível visualizar danos ainda maiores.

De acordo com Lilian Milnitsky Stein e Giovanni Kuckartz (2001, p. 253 apud ROEDIGER; MCDERMOTT, 2000) "[...] as falsas memórias referem-se ao fato de lembrarmos de eventos que na realidade não ocorreram. Informações são armazenadas na memória e posteriormente recordadas como se tivessem sido verdadeiramente vivenciadas". Em suma, as memórias falsas são recordações de fatos irreais, isto é, há uma lembrança real de um evento que nunca aconteceu.

Neufeld, Brust e Stein (2010, p.21) narram a história de Elizabeth Loftus quando jovem, hoje, um dos nomes mais insignes do estudo das falsas memórias, que sofreu a incorporação de um evento falso. No que tange ao episódio, é possível extrair o seguinte trecho:

\footnotetext{
Uma jovem americana perde sua mãe afogada na piscina de casa aos 14 anos. Passados 30 anos, um tio comenta em uma reunião de família que a jovem foi a primeira a encontrar a mãe boiando na piscina. A partir deste momento, ela passa a lembrar vividamente a impactante cena que teria presenciado. Alguns dias depois, ela recebe um telefonema do irmão, desculpando-se pelo tio, informando que ele havia se confundido e que na realidade quem encontrou a mãe na piscina fora sua tia.
}

Assim, diante da maleabilidade da memória, como ora já visto, é notável que Loftus sofreu uma ingerência da memória humana, agregando um evento em sua mente após receber estímulos externos, que, no entanto, não verificou-se.

Carmem Neufeld, Priscila Brust e Lilian Stein (2010, p. 21-22) alertam para o fato de que as falsas memórias podem ser mais detalhadas e vívidas do que as memórias verídicas. Além disso e ainda segundo as autoras, as memórias falsificadas não são mentiras ou fantasias, na realidade, são similares às memórias verdadeiras no que tangem a base cognitiva, bem como, a neurofisiológica. A grande distância entre ambas reside na anexação de informações irreais, por parte das memórias falsificadas. 
Nessa perspectiva, cabe ressaltar que as falsas memórias são tidas como verdadeiras para o indivíduo que as incorpora, não havendo abertura para má-fé. Portanto, a pessoa que agrega um fato falso, acredita em sua realidade. Por outro lado, é importante mencionar que a memória falsa faz parte do funcionamento natural do cérebro, não constituindo-se uma doença (TRINDADE, 2012, p.222).

Dito isso, convém identificar as maneiras pelas quais as memórias falsas podem ser vinculadas à memória, isto é, como elas podem surgir. Em relação ao assunto, Cristina Di Gesu (2019, p.128) expõe que “As falsas memórias não giram apenas em torno de um processo inconsciente ou involuntário de "inflação da imaginação" sobre um determinado evento". Por isso, existem duas possibilidades para a formação de memórias falsas, quais sejam: por fatores internos/endógenos ou por fatores externos/exógenos.

Assim sendo, consoante Carmem Neufeld, Priscila Brust e Lilian Stein (2010, p.25) as falsas memórias quando desenvolvidas por meio de elementos internos, são produto de distorções endógenas ao sujeito e “[...] Essas distorções, também denominadas de auto sugeridas, ocorrem quando a lembrança é alterada internamente, fruto do próprio funcionamento da memória, sem a interferência de uma fonte externa à pessoa".

No caso das falsas memórias internas ou endógenas, fala-se em manifestação espontânea, uma vez que o surgimento se dá de modo natural, sem uma instigação externa à pessoa que a incorpora. Em situações assim, segundo Neufeld, Brust e Stein (2010, p. 25) uma inferência ou interpretação pode passar a ser assimilada à informação original e, de forma consequente, afetar a fidedignidade da lembrança.

Por sua vez, as memórias falsas promovidas por componentes externos, são resultados de sugestões exógenas. Nessa seara, segundo Neufeld, Brust e Stein (2010, p. 26) “[...] após presenciar um evento, transcorre-se um período de tempo no qual uma nova informação é apresentada como fazendo parte do evento original, quando na realidade não faz". Em conjunturas assim, a sugestão pode ser proposital ou não, no que tange a intenção de falsificar uma memória.

Em se tratando de memórias falsas externas ou exógenas, existem suscitações contra a pessoa que relembra a informação falsa e essas suscitações, de forma intencional ou não, são 
indicadas como sendo reais, quando na verdade não são. Posteriormente, por meio da sugestão externa ao indivíduo, a falsa memória é incorporada e anexada à original.

Sobre a sugestão, Robert Sternberg (2008, p. 208) ao tratar das distorções de memória, reporta-se a sugestionabilidade, aduzindo que "[...] As pessoas são suscetíveis a sugestões, de forma que, se lhes for sugerido que viram algo, podem pensar que lembram".

Destarte, é possível sintetizar que as falsas memórias são a incorporação de fatos irreais mas que são tidos como verdadeiros, podendo surgir por meio de processos internos e naturais ou externos e sugeridos à pessoa que sofre a ingerência de agregação de memórias falsas. Nesse rumo de ideias, é possível salientar que apesar de o aspecto inócuo, as falsas memórias podem promover consequências críticas para diversas circunstâncias, em especial, para o Direito Processual das Famílias, levando em consideração a sistemática probatória dependendo da memória.

\section{A REPERCUSSÃO DAS FALSAS MEMÓRIAS NA PROVA DO DIREITO DAS FAMÍLIAS}

A repercussão que as falsas memórias têm no Direito das Famílias é ampla, podendo gerar consequências tanto no ambiente familiar, quanto nos conflitos de família. É possível fazer referência, à título exemplificativo, que as memórias falsas podem surtir efeitos na prática de alienação parental, quando em situações de ruptura da vida conjugal ou de união estável, são realizados atos de destruição, vingança e desmoralização por parte, em regra, de um genitor em desfavor de outro (PIVA, 2018, p.16).

Nesse sentido, é possível que ocorra a sugestão de memórias falsificadas em conjunturas envolvendo a alienação parental. Contudo, destaca-se que a problemática do presente artigo gravita em torno dos efeitos da falibilidade da memória humana para o Direito Processual das Famílias, de maneira que limita-se ao enfoque das possíveis consequências das falsas memórias nas provas do Direito das Famílias.

Os estudos acerca dos impactos das falsas memórias para o sistema probatório no Brasil, são, em regra, de natureza processual penal, de modo que as análises voltadas para a prova do 
Direito das Famílias correlacionada ao fenômeno das memórias falsas, ainda são escassas. Todavia, o assunto apresenta-se como urgente, uma vez que diante da ausência de discussões científicas referentes ao tema, a falibilidade da memória humana continua a produzir danos e riscos para a prova processual.

Como já visto, a memória humana é falha e pode incorporar fatos irreais, de modo espontâneo ou sugerido, o que coloca em xeque a sua confiabilidade. De encontro a isso, existe um sistema de valoração das provas dependentes da memória, o que por conseguinte também promove reflexão acerca de sua fidedignidade. E no Direito das Famílias, o tema envolvendo a prova, ainda é encarado como ponto delicado por conta de sua complexidade.

Por uma visão clássica, é possível mencionar Francesco Carnelutti (2009, p.63) ao fazer alusão sobre a incumbência da prova, nesse sentido, o autor afirma que "As provas servem, precisamente, para voltar atrás, ou seja, para fazer ou, melhor ainda, para reconstruir a história". Resta claro que na produção de uma prova, há simultaneamente, toda uma atividade recognitiva.

Sobre a atividade recognitiva desempenhada na produção probatória, Cristina Di Gesu $(2019$, p.50) expõe "E por que atividade retrospectiva ou recognitiva? [...] O fato é aportado ao processo por meio da prova. Assim, faz-se uma retrospectiva daquilo que aconteceu com a finalidade de sanar a falta de conhecimento do julgador”. Assim dizendo, as alegações feitas são declaradas em um processo por meio da prova e a existência de uma prova cuja dependência habita na memória, exige a retrospecção, em outras palavras, o retorno, a evocação à informações anexadas à memória humana.

Independente da natureza do processo, seja ele do Direito das Famílias, do Direito Penal ou do Direito do Trabalho, entre outros tantos, o destaque que a prova possui é profundo, haja vista que, como destaca Rolf Madaleno (2020, p.297) “A função da prova processual é fornecer ao juiz os elementos e argumentos de sua decisão, afastando suas dúvidas e inquietações, para que possa concluir com convicção e segurança".

No Direito das Famílias, a questão probatória é um tanto quanto complexa por natureza, como relata Fernanda Tartuce (2019, p. 123):

Em processos de família, a dificuldade probatória tende a ser marcante. Além de haver a natural ocultação de fatos desfavoráveis pelos causadores (como ocorre em toda lide), há ainda obstáculos adicionais: nem sempre é possível demonstrar o que ocorreu na intimidade do lar; quando há 
testemunhas, por exemplo, elas costumam ser impedidas, suspeitas ou incapazes.

Assim, a prova nos litígios familiaristas carregam consigo dificuldades naturais relativas a distintas questões e conjuntamente a isso, está a não confiabilidade dos elementos probatórios dependentes da memória, posto o seu traço imperfeito. Em suma, se há uma complicação genuína na sistemática probatória do Direito das Famílias, suscitá-las em correlação com as implicações das memórias falsas, é refletir sobre o quão mais melindrosa a prova possa ser.

No Brasil, o Código Civil (CC) traz disposições acerca da prova a partir de seu artigo 212, também, o Código de Processo Civil (CPC) regulamenta as provas em seu capítulo XII, a partir do artigo 485 e o Direito das Famílias segue o seu regramento por não ainda possuir um Código de Processo próprio, assim como, observa o disciplinado no Código Civil.

Das modalidades de provas elencadas pelo Código Civil, tanto a confissão, quanto a prova testemunhal, são provas que fazem uso da memória humana para serem concretizadas. No que toca o Código de Processo Civil, é possível citar como provas que também utilizam a memória humana, além da confissão e da prova testemunhal que também são reguladas pelo CPC, o depoimento pessoal e a prova pericial, primordialmente as perícias com abordagens psicológicas.

Além disso, a Lei de $\mathrm{n}^{\circ}$ 13.431/2017 que estabelece o sistema de garantias da criança e do adolescente, em seu título III, a partir do artigo $7^{\circ}$ até o artigo 12, cuida da escuta especializada e do depoimento especial. Este, por sua vez, seguirá as regulamentações da produção de prova antecipada, conforme destaca o artigo 11, da referida lei. Ainda, no Direito das Famílias pátrio, em determinadas circunstâncias são admitidas as provas ilícitas, assim como, há uma diversificação acerca dos meios probatórios.

Perante o exposto, as provas que têm na memória as suas razões existenciais, são provas frágeis, uma vez que se apoiam em um elemento também muito sensível e como já estudado, durante os processos de recriar eventos passados para o fim probatório, é plenamente possível que falsas memórias sejam incorporadas.

De acordo com Rafael Altoé e Gustavo Noronha de Ávila (2017, p. 258) ao tratarem dos aspectos cognitivos da memória e a antecipação da prova testemunhal penal, reforçam a realidade de que na construção da memória, fatores endógenos e exógenos são relacionados e exprimem que “[...] A emoção, o ambiente externo, a capacidade de atenção, o cansaço, 
dentro outros aspectos, são alguns fatores que promovem atuação conjunta para a memória". O mesma ponderação emprega-se ao Direito Processual das Famílias.

Assim, na produção da prova, diversos agentes podem contribuir para a incorporação de informações irreais, incluindo a própria colheita das provas, o modo pelo qual essas provas são exploradas, os questionamentos e a maneira que são feitas as indagações, além do contexto e do tempo, dentre outros fatores.

Ainda conforme Altoé e Noronha (2017, p.262):

A construção da memória pode condizer, ainda que por bastante aproximação, com a realidade do episódio vivenciado. Sem dúvida alguma não significa, como uma leitura precipitada pode fazer crer, que todo e qualquer relato é confiável. Apenas significa que não deve ser tão confiável como ordinariamente se faz crer. Significa, ainda, pela importância que carrega, que a memória não deve ser ignorada quando do estudo da prova testemunhal e que deve ser encarada como fenômeno complexo que é, merecendo, acima de tudo, treinamento e aperfeiçoamento de técnicas que melhor se adaptem às atuais descobertas da psicologia do testemunho.

A consideração dos autores tem como centro a prova testemunhal, no entanto, é aplicável a todas as provas dependentes da memória, na medida em que a memória deve ser vista com a devida atenção para que a sua falibilidade não produza danos, o que restou evidente que é possível de acontecer.

Logo, as provas que necessitam da memória humana, possuem uma natureza rúptil pela própria essência falível da memória. No processo probatório, falsas memórias podem ser inseridas e erros podem surgir. Tal conjuntura pode afetar, inclusive, os direitos da personalidade, o que será visto a seguir.

\section{AS FALSAS MEMÓRIAS E A PROVA DO DIREITO DAS FAMÍlIAS: A REPERCUSSÃO DE TAL CONJUNTURA NOS DIREITOS DA PERSONALIDADE}

A problemática deste artigo, isto é, as consequências que um dos frutos da falibilidade da memória humana, as falsas memórias, pode promover para as provas do Direito das Famílias que dependem da memória e de modo consequente, para os direitos da personalidade, resultou a análise interdisciplinar do funcionamento da memória, bem como, das memórias falsificadas, dos efeitos que as falsas memórias podem causar nas provas 
familiaristas e agora, da inferência de toda essa circunstância para os direitos da personalidade.

Aqui, faz-se necessário salientar o porquê da correlação com os direitos da personalidade. Nesse sentido, o Direito das Famílias é um ramo que se debruça a cuidar não só de direitos de ordem patrimonial, cuidando também daqueles de ordem existencial, cuja relação é forte com os direitos da personalidade, aqueles cuja a existência é de caráter essencial para a formação da personalidade humana, assim havendo interferências da falibilidade da memória humana nas provas do processo das famílias, tais direitos, como resultado, serão atingidos.

Cabe destacar a própria função social da família, que se correlaciona com os direitos da personalidade uma vez que consiste na propiciação do desenvolvimento da personalidade de seus membros. Leonel Rocha e Júlia Scherbaum (2018, p.11) expressam essa questão, ao exporem que '"[...] a família perde sua função tradicional de reprodução econômica e passa a ser pensada como responsável pela realização pessoal de seus membros".

De acordo com Limongi França (2011, p.653 apud SAVIGNY) existem três esferas sob as quais recaem as relações jurídicas, são elas: I) o mundo exterior, II) a pessoa na família e III) a própria pessoa, nessa perspectiva, "Ao mundo exterior correspondem os Direitos Patrimoniais. A pessoa ampliada na família, os Direitos da Família. A própria pessoa, os Direitos da Personalidade [...]”.

Para Anderson Schreiber (2014, p. 13), de forma clara e direta, os direitos da personalidade são atributos fundamentais da pessoa humana. Isso significa que os direitos da personalidade são direitos que promovem a própria concretização da condição pessoal de cada indivíduo, uma vez que tais direitos dizem respeito aos elementos que pessoalizam os sujeitos.

Nesse seguimento, vai de encontro a lição de Carlos Alberto Bittar (2015, p.29) ao enfatizar que "Consideram-se da personalidade os direitos reconhecidos à pessoa humana tomada em si mesma e em suas projeções na sociedade, previstos no ordenamento jurídico exatamente para a defesa de valores inatos no homem".

Conforme as lições de Adriano De Cupis (2008, p.24): 
[...] existem certos direitos sem os quais a personalidade restaria uma susceptibilidade completamente irrealizada, privada de todo o valor concreto: direitos sem os quais todos os outros direitos subjetivos perderiam todo o interesse para o indivíduo - o que equivale a dizer que, se eles não existissem, a pessoa não existiria como tal. São esses os chamados ' direitos essenciais" com os quais se identificam precisamente os direitos da personalidade $[\ldots]$.

Dessa forma, é possível compreender os direitos da personalidade como sendo os direitos imprescindíveis à formação da personalidade humana, aqueles direitos sem os quais, a personalidade restaria prejudicada. No Código Civil estão registrados alguns deles, como a vida, o nome, a imagem e a vida privada, por exemplo, todavia, existem outros tantos.

Nas palavras de Cleide Fermentão (2006, p.245):

Por meio dos direitos da personalidade, o ser humano tem tutelados pelo Direito a garantia e o respeito a todos os elementos, potencialidades e expressões da personalidade humana. Essa garantia abrange toda a esfera individual, acrescentando-lhe o respeito a valores como o sentimento, a inteligência, a vontade, a igualdade, a segurança e o desenvolvimento da personalidade.

Assim, é por intermédio dos direitos da personalidade que aqueles componentes essenciais à pessoa são alcançados pela proteção. Dentro desse âmbito, é de extrema importância frisar que além do Direito, a família também é um agente protetor de tais elementos, uma vez que a organização familiar fornece o ambiente adequado ao desenvolvimento da personalidade.

Ainda, Fernanda Tartuce ao tratar das provas do Direito das Famílias, registra que as causas familiares difundem questões de direito personalíssimo (TARTUCE, 2019, p. 128). Nessa ordem de ideias e diante de toda a análise dos direitos da personalidade, cabe evidenciar que nos litígios envolvendo o agrupamento familiar, que lidam com os direitos personalíssimos, as provas dependentes da memória são peças de extrema importância para o desfecho do processo, por isso, a necessidade de um olhar atento sobre elas.

Uma prova é capaz de alterar o resultado de uma lide e isso pode promover inúmeras repercussões aos direitos da personalidade dos envolvidos, podendo afetar a integridade psicofísica e moral, como a vida, a liberdade, a intimidade, a honra, a imagem, a identidade, entre outros tantos direitos da personalidade. 
Assim, sendo a memória humana falha e suscetível a incorporação de fatos irreais, tudo o que dela depende, tem o seu mesmo caráter, ou seja, frágil. Logo, com as provas a consideração é a mesma e estando perante as provas do Direito das Famílias, todo cuidado deve ser concedido, em virtude da ofensa aos direitos da personalidade que pode ser ocasionada mediante a existência de falsas memórias em polo probatório.

\section{CONCLUSÃO}

Perante à problemática do presente artigo, assim como de todo conteúdo apresentado em relação a repercussão que a falibilidade da memória humana, por meio das falsas memórias, pode acarretar para as provas que dependem da memória no Direito das Famílias, assim como nos direitos da personalidade, é possível concluir que:

A análise que correlaciona as falsas memórias e os seus impactos na esfera jurídica, exige um estudo interdisciplinar, no caso deste trabalho, além dos ensinamentos do Direito, foram necessárias as lições da Neurociência e da Psicologia Cognitiva. Ao serem trabalhados em conjunto, os preceitos das três áreas distintas, no entanto complementares, formaram um novo conhecimento, resultando o próprio objetivo da interdisciplinaridade.

A memória enquanto processo de codificação, armazenagem e evocação de informações, apesar de toda a sua essencialidade para as pequenas e grandes circunstâncias da vida humana, bem como, para a própria individualização dos sujeitos, não funciona de forma absoluta e perfeita, funciona, na verdade, de maneira falha, inexata e em suas fases de formação, é suscetível a erros, podendo incorporar fatos irreais, ou seja, as falsas memórias.

As falsas memórias, por sua vez, são a recordação de eventos que nunca ocorreram ou que aconteceram de maneira diversa da lembrada. Dois aspectos de forte valor que são necessários destacar acerca das memórias falsificadas, são: primeiro, as falsas memórias não são uma doença, são parte do funcionamento natural do cérebro e segundo, as falsas memórias não são eivadas de má-fé, não constituem uma mentira, são a verdade como o sujeito acredita. 
Em casos frívolos do cotidiano normal, as falsas memórias podem ser encaradas como não sendo danosas, todavia ao serem abordadas dentro de uma atmosfera jurídica, é possível notar que as suas impressões podem ser drásticas, propiciando inúmeros prejuízos de diversas naturezas, podendo lesar direitos, inclusive.

As provas têm função importante dentro de um processo, uma vez que são encarregadas do fornecimento dos elementos necessários para o convencimento do magistrado, mas têm também uma atividade inerente, a atividade recognitiva, em outras palavras, a atividade por meio da qual fatos são revisitados. Assim, entende-se que todas as provas dependem da memória humana, contudo, em algumas a dependência é direta e maior.

Nas provas dependentes, de forma direta, da memória, é necessário que haja um olhar mais atento, visto que a memória é falha e passível de erros, consequentemente, tais provas também possuem cunho delicado. Se a memória pode absorver eventos irreais, as provas que dela dependam podem ser danificadas.

E sendo as provas do Direito das Famílias, a atenção deve ser redobrada, uma vez que o impacto da imperfeição da memória humana pode causar sobre a sistemática probatória familiarista é ainda mais complexa, na medida em que o Direito das Famílias cuida de direitos de extrema relevância pessoal, assim como, da entidade que promove a ambiência adequada ao desenvolvimento individual de seus membros por meio da formação da personalidade humana.

Os direitos essenciais à pessoa humana possuem íntima ligação com a entidade familiar e em sede de conflito, tal ligação não é extinta. Logo, havendo a incorporação de uma falsa memória e a sua repercussão em uma prova do Direito das Famílias, o processo pode tomar rumos diferentes e, o mais importante, frente a tal circunstância, direitos serão atingidos, em especial, os direitos da personalidade, sejam os de ordem psicofísica ou sejam os de ordem moral.

Portanto, é possível concluir que é plenamente possível e mais fácil do que se possa imaginar que as falsas memórias afetem o sistema probatório do Direito das Famílias e consequentemente, promovam danos aos direitos da personalidade.

\section{REFERÊNCIAS}


ALTOÉ, Rafael; ÁVILA, Gustavo Noronha de. Aspectos Cognitivos da memória e a antecipação da prova testemunhal no processo penal. Revista Opinião Jurídica, Fortaleza, v.15, n.20, p.255-270, jan./jun. 2017. Disponível em:

https://periodicos.unichristus.edu.br/opiniaojuridica/article/view/1272. Acesso em 01 set. 2020.

BITTAR, Carlos Alberto. Os direitos da personalidade. 8. ed. São Paulo: Saraiva, 2015.

BRASIL. Lei n. 10.406, 10 de janeiro de 2002. Institui o Código Civil. Diário Oficial da União, Brasília, DF, 10 jan. 2002. Disponível em:

http://www.planalto.gov.br/ccivil_03/leis/2002/110406.htm. Acesso em: 31 ago. 2020.

BRASIL. Lei n. 13.105, 16 de março de 2015. Institui o Código de Processo Civil. Diário Oficial da União, Brasília, DF, 15 mar. 2015. Disponível em:

http://www.planalto.gov.br/ccivil_03/_ato2015-2018/2015/lei/l13105.htm. Acesso em: 31 ago. 2020.

BRASIL. Lei 13.431, 4 de abril de 2017. Estabelece o sistema de garantia de direitos da criança e do adolescente vítima ou testemunha de violência e altera a Lei $\mathrm{n}^{\circ}$ 8.069, de 13 de julho de 1990 (Estatuto da Criança e do Adolescente). Diário Oficial da União, Brasília, DF, 4 abr. 2017. Disponível em: http://www.planalto.gov.br/ccivil_03/_ato2015-

2018/2017/lei/113431.htm. Acesso em: 31 ago. 2020.

CARNELUTTI, Francesco. As misérias do processo penal. Tradução: Carlos Eduardo Trevelin Millan. São Paulo: Editora Pillares, 2009.

CUPIS, Adriano De. Os Direitos da Personalidade. São Paulo: Quorum, 2008.

DAMÁSIO, Antônio R. O erro de Descartes: emoção, razão e o cérebro humano. São Paulo: Companhia das Letras, 2001.

DI GESU, Cristina. Prova penal e falsas memórias. 3. ed. Porto Alegre: Livraria do Advogado, 2019.

FAZENDA, Ivani Catarina Arantes. Integração e interdisciplinaridade no ensino brasileiro: Efetividade ou ideologia. São Paulo: Edições Loyola, 2011.

FERMENTÃO, Cleide Aparecida Gomes Rodrigues. Os direitos da personalidade como direitos essenciais e a subjetividade do direito. Revista Jurídica Cesumar, Maringá, v.6, n.1, p.241-266, 2006. Disponível em:

https://periodicos.unicesumar.edu.br/index.php/revjuridica/article/view/313. Acesso em: 04 set. 2020 .

FRANÇA, Rubens Limongi. Direitos da Personalidade: Coordenadas fundamentais. In: MENDES, Gilmar Ferreira; STOCO, Rui (org.). Coleção doutrinas essências: direito civil, parte geral. São Paulo: Revista dos Tribunais, 2011, v.3. 
IZQUIERDO, Ivan. Memória. $3^{\mathrm{a}}$ ed. Porto Alegre: Editora Artmed, 2018.

IZQUIERDO, Ivan. Questões sobre a memória. São Leopoldo: Unisinos, 2004.

JAPIASSU, Hilton. Interdisciplinaridade e patologia do saber. Rio de Janeiro: Imago, 1976.

KIHLSTROM, John F. Exhumed Memory. University of California. Disponível em: https://www.ocf.berkeley.edu/ jfkihlstrom/exhumed.htm. Acesso em: 30 ago. 2020.

MADALENO, Rolf. Direito de Família. 10. ed. Rio de Janeiro: Forense, 2020.

NEUFELD, C. B; BRUST, P. G.; STEIN, L. M. Compreendendo o fenômeno das falsas memórias. In: STEIN, Lilian Milnitsky (org.). Falsas memórias: fundamentos científicos e suas aplicações clínicas e jurídicas. Porto Alegre: Artmed, 2010.

OLIVEIRA, Alcyr Alves. Uma breve história da pesquisa da memória. In: OLIVEIRA, Alcyr Alves (org). Memória: Cognição e comportamento. São Paulo: Casa do Psicólogo, 2007.

PIVA, Rui Carvalho. Alienação parental na vigência do casamento e da união estável e tutela coletiva. Revista de Constitucionalização do Direito Brasileiro - RECONTO. Maringá, v. 1, n. 2, p. 1 - 21, 2018. Disponível em:

http://revistareconto.com.br/index.php/Reconto/article/view/59. Acesso em: 07 set. 2020.

ROCHA, Leonel Severo. SCHERBAUNM, Júlia Francieli Neves. A constitucionalização no direito de família no sistema jurídico brasileiro. Revista de Constitucionalização do Direito Brasileiro - RECONTO. Maringá, v. 1, n.1, p. 1 - 21, 2018. Disponível em: https:// http://revistareconto.com.br/index.php/Reconto/article/view/62. Acesso em: 07 set. 2020.

ROEDIGER, Henry L.; MCDERMOTT, Kathleen B. Tricks of Memory. Department of Psychology, Washington University, v.9, n.4, ago., 2000.

SCHREIBER, Anderson. Direitos da personalidade. 3. ed. São Paulo: Atlas, 2014.

STEIN, Lilian Milnitsky; PERGHER, Giovanni Kuckartz. Criando falsas memórias em adultos por meio de palavras associadas. Psicologia: Reflexão e Crítica, Porto Alegre, v.14, n.2, p. 353-366, 2001. Disponível em: https://www.scielo.br/scielo.php?pid=S010279722001000200010\&script=sci_abstract\&tlng=pt. Acesso em: 30 ago. 2020.

STERnBERG, Robert J. Psicologia Cognitiva. 4. ed. Porto Alegre: Artmed, 2008.

TARTUCE, Fernanda. Processo civil no direito de família: teoria e prática. 4. ed. Rio de Janeiro: Forense; São Paulo: MÉTODO, 2019.

TRINDADE, Jorge. Manual de Psicologia Jurídica para operadores do Direito. 6. ed. Porto Alegre: Livraria do Advogado Editora, 2012. 
